\title{
PeRSPECTIVA HISTÓRICA DA EDUCAÇÃO PROFISSIONAL E TECNOLÓGICA NO BRASIL: A CONSTITUIÇÃO DA DOCÊNCIA NA EDUCAÇÃO SUPERIOR EM TEMPOS DE GLOBALIZAÇÃO
}

\author{
ELISABETE FERREIRA BORGES \\ Universidade de Uberaba (UNIUBE), Uberaba, Minas Gerais, Brasil
}

\begin{abstract}
REsumo: Analisar a educação superior na Rede Federal de Educação Profissional, em um contexto de globalização caracterizado como uma realidade complexa e desafiadora, constituiu-se no objetivo deste artigo. Tendo como referencial teórico autores críticos à Teoria do Capital Humano, o estudo adotou como procedimento metodológico dois movimentos interligados: a pesquisa bibliográfica e a documental. A educação superior, nessa rede de ensino, encontra-se em fase de estruturação e consolidação. O desafio que se coloca é o de resgatar a enorme dívida em relação à maioria de brasileiros condenados à marginalidade a partir de uma herança histórica perversa e acentuada com o rearranjo econômico globalizado, que exclui milhares de pessoas de conquistas que a humanidade conseguiu por meio do capital e do desenvolvimento científico e tecnológico.
\end{abstract}

Palavras-chave: Educação superior. Educação profissional. Educação Tecnológica. Globalização.

\section{INTRODUÇÃO}

Neste artigo, um resgate histórico analisa o início da oferta da educação superior na rede federal de educação profissional, científica e tecnológica e suas implicações na produção de conhecimento em tempos de globalização. Dois itens fazem a contextualização sócio histórica da educação profissional: em um primeiro momento, analisa-se a construção da cultura organizacional das instituições voltadas para a educação profissional e tecnológica a partir de uma perspectiva histórica; no segundo momento trata-se da criação da Rede Federal de Educação Profissional, Científica e Tecnológica e dos Institutos Federais de Educação, Ciência e Tecnologia (IF), caracterizando aspectos legais e diretrizes gerais de organização, estes últimos os diferenciam de outras instituições educacionais. Nas considerações finais, aponta-se para a complexidade da reconstrução da identidade educacional e docente utilizando o diálogo, a tolerância, o respeito, a solidariedade e a consciência crítica sobre a história como possibilidade de atuação do educador enquanto trabalhador e intelectual. $\mathrm{Na}$ perspectiva de uma pedagogia da esperança, busca-se a construção de um mundo harmonioso com possibilidades de vida mais digna e humana para a maioria dos brasileiros. 


\section{CULTURA ORGANIZACIONAL: PERSPECTIVA HISTÓRICA DA EDUCAÇÃO PROFISSIONAL}

A constituição da docência se revela no cotidiano das instituições. O contexto institucional apresenta forças internas e externas que, simultaneamente, determinam a constituição e reconstituição permanente da docência enquanto um fazer reflexivo, único e peculiar. Dessa forma, a compreensão dessa ação docente pressupõe conhecer a cultura organizacional existente, que resulta de uma construção histórica, com seus valores, possibilidades, limites e restrições.

De fato, para compreender a dinâmica de constituição da docência nos Institutos Federais (IF), enquanto instituições voltadas para a educação profissional, científica e tecnológica, faz-se necessário analisar a ação educativa integrada ao mundo produtivo em uma perspectiva histórica, uma vez que ela impõe exigências específicas ao trabalho docente, que, por sua vez, se constituem em demandas formativas. Essa compreensão elucida elementos para a proposição de modos de intervenção nessa territorialidade posta.

O contexto dos IF's apresenta-se como uma realidade repleta de sentidos, saberes, concepções e práticas que interferem diretamente no processo pelo qual o professor se constitui e reconstitui continuamente. Uma breve retrospectiva histórica da educação profissional pode proporcionar uma compreensão do que é necessário para fortalecer e/ou alterar a cultura institucional e proporcionar condição ao docente para uma atuação que responda aos novos desafios colocados fortemente pela globalização (BRASIL, 2009).

De fato, o fenômeno da globalização, nesse início do século XXI, apresenta-se como um contexto complexo, desafiador e pouco compreendido, com implicações acentuadamente desumanas. A globalização, além de criar dificuldades econômicas decorrentes do distanciamento cada vez mais acentuado entre países ricos e países pobres, tem determinado um processo de imigração intenso, em escala mundial, que suscita o crescimento do racismo e da xenofobia e aumenta a exclusão de milhares de pessoas por meio do desemprego, subemprego e desalento característico daqueles indivíduos que perderam a esperança de inserção no mercado de trabalho.

É nesse contexto que surge na Rede Federal de Educação Profissional, Científica e Tecnológica, e em particular nos Institutos Federais, os cursos de educação superior propostos simultaneamente com os cursos técnicos e os de formação básica de trabalhadores. Contexto este que impõe desafios postos pelas políticas educacionais vigentes e pela realidade socioeconômico/cultural, e deve ser enfrentado com o acréscimo desse nível de educação - a superior e os seus desdobramentos em graduação e pós-graduação lato e stricto sensu -, constituindo-se em mais uma atribuição institucional. A compreensão histórica da constituição da educação profissional no Brasil fornece elementos valiosos para uma análise crítica do papel das instituições responsáveis por essa modalidade de educação e para uma inserção profissional docente necessária.

A trajetória da educação profissional no Brasil pressupõe a análise das relações com o trabalho vinculado ao modo de produção capitalista. A origem escravocrata da sociedade brasileira e, posteriormente, a divisão entre patrões e empregados deu origem à fragmentação do trabalho. O menosprezo e o preconceito pelo trabalho e pelas 
atividades manuais em contraposição à valorização da atividade intelectual vão marcar de modo permanente todo o percurso da educação brasileira, em especial da educação profissional, deixando marcas que, ainda nas primeiras décadas do século XXI, se fazem presente (CIAVATTA, 2015).

No início do século XX, com a organização de pequenos núcleos urbanos, surge a presença de pessoas desamparadas. Para tentar resolver essa situação são criadas escolas com um cunho assistencialista, que tinham por finalidade acolher jovens órfãos e desafortunados e ensinar-Ihes um ofício que pudesse lhes garantir a sobrevivência. Esse fato vai constituir-se no marco inicial da Rede Federal de Educação Profissional, Científica e Tecnológica ocorrido em 1909, quando o então Presidente da República, Nilo Peçanha, criou 19 escolas de Aprendizes e Artífices.

Essas escolas, mais tarde, foram transformadas em escolas técnicas e agrotécnicas, posteriormente, em Centros Federais de Educação Profissional e Tecnológica (Cefet) e, finalmente, em 2008, em Institutos Federais de Educação Profissional. As escolas de Aprendizes e Artífices foram criadas pelo Decreto n. 7.566, de 23 de setembro de 1909 e, naquela época, ficaram subordinadas ao Ministério dos Negócios da Agricultura, Indústria e Comércio. Eram as primeiras escolas técnicas instituídas pelo governo federal (PEREIRA, 2018).

Segundo Ciavatta (2015), nessas escolas os jovens aprenderiam atividades artesanais e agrícolas, o trabalho manual. Já as escolas destinadas à elite preparavam para o trabalho intelectual. Essa dualidade entre trabalho manual e intelectual, presente desde o início da República, vai permanecer de modo acentuado durante toda a trajetória da educação brasileira, em especial no segmento destinado à formação profissional. Trajetória esta que implica o estabelecimento de relações com o trabalho vinculado ao modo de produção capitalista. A sociedade brasileira dividida entre patrões e empregados será marcada pela fragmentação entre trabalho manual e intelectual. Portanto, em sua origem, a educação profissional destinava-se aos jovens das classes sociais "menos favorecidas" do ponto de vista econômico, e, em 2008, a Rede Federal de Educação Profissional constituiu-se como referência no acolhimento de todas as pessoas para que tenham efetivo acesso às conquistas científicas e tecnológicas.

Com a criação do Ministério da Educação e Saúde Pública, em 14 de novembro de 1930, essas Escolas de Aprendizes e Artífices passam a ser supervisionadas pelo órgão recém-criado - a Inspetoria do Ensino Profissional Técnico. Nessa década de 1930, após o término da Primeira Guerra Mundial e a crise de 1929, há dificuldade de continuar importando bens manufaturados. Diante desse fato, com a crescente urbanização e o início do processo de industrialização, uma nova ideologia vai permear um projeto de país que contempla uma proposta de educação profissional necessária à preparação de profissionais para suprir as novas demandas de trabalho. $O$ trabalho artesanal e agrícola passa progressivamente a ser substituído e/ou ampliado pelo trabalho industrial. A escola assume o papel de formar a mão de obra para atuar na indústria, gerando capital para a burguesia - classe social detentora do poder econômico, social e político.

A Lei n. 378/37 aprovada em 13 de janeiro de 1937, pelo então presidente Getúlio Vargas, transforma as Escolas de Aprendizes e Artífices em Liceus Industriais. A dualidade estrutural permanece e as escolas são organizadas de forma diferenciada para clientelas distintas. Os filhos da burguesia recebiam formação generalista que abrangia conhecimentos sobre ciências, arte, política e cultura. Para os filhos dos trabalhadores era 
destinada uma educação que possibilitasse o imediato ingresso no mercado de trabalho. Competia à escola disciplinar os trabalhadores para a obediência às leis do mercado, por meio da transmissão de ideais e valores da sociedade vigente. A escola é uma instituição que dissemina ideologias em suas práticas no campo do conhecimento, valores e atitudes e, ao mesmo tempo, articula ou desarticula interesses. Tal contexto desencadeia um contínuo questionamento sobre os saberes e as intenções presentes na prática pedagógica.

A participação da Força Expedicionária Brasileira na Segunda Guerra Mundial e o consequente empréstimo financeiro dos Estados Unidos ao Brasil no Governo Getúlio Vargas impulsionaram a industrialização brasileira. A concretização do processo de industrialização vai exigir mão de obra qualificada. Esse aspecto torna-se um marco importante para desencadear várias reformas do ensino no país, dentre elas as relativas ao ensino profissional.

Na década de 1940, foram homologadas várias leis sob a coordenação de Gustavo Capanema, Ministro da Educação e da Saúde Pública, cujo objetivo era o de remodelar todo o ensino no país. São as leis orgânicas que alteraram de modo significativo o ensino, em especial o ensino profissional, que passa a ser ofertado em dois níveis: curso básico industrial, artesanal, de aprendizagem e de mestria; e o segundo nível, curso técnico industrial, agrícola e comercial. O segundo nível é equiparado ao de nível médio. O Decreto n. 4.127, de 25 de fevereiro de 1942 transforma os Liceus Industriais em Escolas Técnicas Industriais, que passam a oferecer a formação profissional em nível equivalente ao do secundário. A partir dessas mudanças, o ingresso nas escolas profissionais passa a exigir exames de admissão.

Durante o governo de Juscelino Kubitschek (1956 a 1961), aprofunda-se a relação entre Estado e economia. Na época, a concepção de que a formação de recursos humanos para o desenvolvimento era fundamental havia sido defendida por Mincer (1958) e Theodore W. Schultz (1963). Sob a influência da Teoria do Capital Humano, formar profissionais orientados para promover o desenvolvimento do país passou a ser uma meta prioritária para o governo que tinha como mote "desenvolver o País: 50 anos em 5 anos". Preparar recursos humanos para promover o desenvolvimento torna-se fundamental.

Nos meados do século XX, o que melhor definia a relação trabalhoeducação na sociedade capitalista contemporânea era a Teoria do Capital Humano. Essa teoria teve origem e base de sustentação numa conjuntura pelo desenvolvimento capitalista marcado pelo crescimento econômico, pelo fortalecimento dos Estados de BemEstar e pela confiança na conquista do pleno emprego (BORGES; FAGIANI, 2018).

Nesse contexto, em 1959, as Escolas Técnicas Industriais, Comerciais e Agrícolas são transformadas em autarquias com o nome de Escolas Técnicas Federais, com autonomia didática e de gestão. Com a promulgação da Lei de Diretrizes e Bases da Educação Nacional n. 4.024, em 20/12/1961, ocorre alterações que equipararam o ensino profissional ao ensino acadêmico. $O$ período foi marcado por profundas mudanças na política de educação profissional, dentre elas o decreto n. 60.731/67 transfere as Fazendas 
Modelos do Ministério da Agricultura para o Ministério da Educação e Cultura, que passam a funcionar como escolas agrícolas.

A dualidade estrutural da escola brasileira presente em suas práticas escolares permanece, alimenta e reforça a discriminação social. Essa trajetória de escola secundária para uns e profissional para outros passa por diferentes momentos e por mudanças nos dispositivos legais. Com a Lei de Diretrizes e Bases do Ensino de Primeiro e de Segundo Graus n. 5692, promulgada em 1971, ocorre a tentativa de implantar compulsoriamente o ensino profissional no país, que não obteve êxito em superar a discriminação cultural, social e econômica que permeia as trajetórias de ensino no Brasil. Essa tentativa era resposta a um novo paradigma que se estabelecia: formar técnicos sob o regime de urgência. Pela primeira vez no Brasil, o ensino profissional passa a ser a referência para a organização da escola, nessa época, denominada de escola de segundo grau.

Diante do fracasso da implantação compulsória da educação profissional, dando prosseguimento às tentativas de organização dessa modalidade de educação, a partir de 1978, tem início a implantação dos Centros Federais de Educação Tecnológica (CEFET). A Lei n. 8.948, de 8 de dezembro de 1994 - que dispõe sobre a Instituição do Sistema Nacional de Educação Tecnológica e dá outras providências -, cria a possibilidade de transformação das escolas técnicas seguindo esse novo modelo. No artigo terceiro, em seu primeiro parágrafo, previa que: a implantação dos CEFET de que trata este artigo será efetivada gradativamente, mediante decreto específico para cada centro, obedecendo a critérios a serem estabelecidos pelo Ministério da Educação e do Desporto, ouvido o Conselho Nacional de Educação Tecnológica. Com essa transformação das escolas técnicas em CEFET inicia-se, nestas instituições, a oferta de cursos superiores de educação profissional.

A Lei n. 6.545, de 1978 transformou três Escolas Técnicas Federais (Paraná, Minas Gerais e Rio de Janeiro) em Centros Federais de Educação Tecnológica. No início da década de 1990, a política pública vigente estabeleceu que a expansão da oferta da educação profissional somente ocorreria em parceria com Estados, Municípios e Distrito Federal, setor produtivo ou organizações não governamentais, que seriam responsáveis pela manutenção e gestão dos novos estabelecimentos de ensino. Há aí uma interrupção desse processo de transformação das escolas em CEFET, que é retomado a partir de 1999, quando, gradativamente, a maioria das escolas técnicas e agrotécnicas foi transformada em CEFET. Essa situação vai perdurar até a criação da Rede Federal de Educação Profissional, Científica e Tecnológica e dos Institutos Federais, em 2008.

A educação superior nos Institutos Federais tem, portanto, uma história recente. Ela surge com a transformação das escolas técnicas federais em CEFET, a partir de 1978, em um contexto de globalização perpassado por revisões epistemológicas contemporâneas. Temas como violência, sexualidade, TIC, identidade, subjetividade, gênero, raça e etnia constituem-se no pano de fundo para os desafios postos para essas e outras instituições educacionais. Com uma proposta inclusiva, tem a pretensão de resgatar a imensa dívida da sociedade brasileira com a maioria da população discriminada e marginalizada. O panorama educacional enquanto segmento social não pode ser "fechado, contido, fixado, reprimido, colonizado. Se for fechado, ele irrompe. Se for contido, ele transborda. Se for fixado, ele excede. Se for reprimido, ele se rebela. Se for colonizado, ele resiste" (TADEU da SILVA, 2000, p. 10). 
A globalização, enquanto nova configuração da economia mundial, atinge também o Brasil, com um cenário que se apresenta caracterizado por profundas e polêmicas mudanças. A intensificação do uso de tecnologias se associa a uma nova configuração dos processos produtivos. Um novo cenário econômico e produtivo se estabelece, com o surgimento de novas tecnologias agregadas à produção e à prestação de serviços. Para atender a uma nova demanda de profissionais exigidos pelo contexto socioeconômico que se configura nas décadas finais do século XX e início do século XXI as instituições de educação profissional vêm buscando diversificar programas e cursos para elevar os níveis de qualidade, bem como a sua maior diversidade.

O trabalho docente insere-se nesse contexto globalizado do trabalho e do trabalhador e pressupõe a análise das suas condições subjetivas e objetivas. $\mathrm{O}$ aspecto subjetivo refere-se à atividade consciente do homem no seu modo de planejar a sua ação com maior ou menor autonomia dependendo das condições objetivas, entendidas como as situações efetivas de seu trabalho. As condições objetivas compreendem a organização escolar e curricular, a situação pedagógica, o planejamento das práticas e das aulas, e inclui, ainda, a remuneração do professor (BORGES; CECÍLIO, 2018, p. 11).

A Lei de Diretrizes e Bases da Educação Nacional n. 9.394, aprovada em vinte de dezembro de 1996, dispõe em um capítulo próprio sobre a Educação Profissional. Em 1997, o Decreto n. 2.208 regulamenta a educação profissional e cria o Programa de Expansão da Educação Profissional (PROEP). Esse Decreto n. 2.208/97 determinou, compulsoriamente, a separação do ensino técnico do ensino médio, que até aquela data era ministrado de forma integrada como um único curso.

Em 2004, o Decreto n. 5.154 revoga o Decreto n. 2.208/97 e flexibiliza a possibilidade de integração do ensino técnico de nível médio ao ensino médio que havia sido proibida pelo Decreto n. 2.208/97. A Lei n. 11.195 , de 2005, dá nova redação ao $\S 5^{\circ}$ do art. $3^{\circ}$ da Lei no 8.948 , de 8 de dezembro de 1994, e estabelece que a expansão da oferta da educação profissional preferencialmente ocorrerá em parceria com Estados, Municípios e Distrito Federal, setor produtivo ou organizações não governamentais. Nesse contexto, foi lançada a primeira fase do Plano de Expansão da Rede Federal, com a construção de sessenta novas unidades de ensino pelo Governo Federal. Nesse ano de 2005, também, o CEFET Paraná é transformado em Universidade Tecnológica Federal do Paraná, a primeira do País.

Em 2006, é lançado o Catálogo Nacional dos Cursos Superiores de Tecnologia. Em 2007 é lançada a segunda fase do Plano de Expansão da Rede Federal, mais 150 unidades são entregues à população e, em 2010, atinge a implantação de 354 unidades. Na III fase do Plano de Expansão, entre 2011 e 2014, são entregues mais 208 novas unidades de educação profissional e a Rede Federal atinge a marca de 643 unidades em atividade no País (BRASIL, 2018).

Em 2008, há uma articulação entre as instituições e o Ministério da Educação, que edita uma Chamada Pública resultante na Lei n. 11.892, de 29 de dezembro de 2008, que, por sua vez, cria a Rede Federal de Educação Profissional, Científica e Tecnológica e os 
Institutos Federais de Educação, Ciência e Tecnologia. Em 2009, é comemorado o centenário da Rede Federal de Educação Profissional, Científica e Tecnológica.

Presente no território nacional, a Rede Federal presta um serviço à nação ao dar continuidade à sua missão de qualificar profissionais para os diversos setores da economia brasileira, realizar pesquisa e desenvolver novos processos, produtos e serviços em colaboração com o setor produtivo. Embora seja relevante todo esse processo de mudança que marcou a educação profissional no País, a dualidade estrutural da escola brasileira continua presente em suas práticas escolares e alimenta e reforça a discriminação social.

A reflexão sobre essa breve perspectiva histórica da educação profissional propicia elementos para compreender uma prática pedagógica tecnicista vivida pelos estudantes e pelos professores em formação, com implicações para a docência constituída política e pedagogicamente. A predominância de uma pedagogia tecnicista presente nessas instituições de ensino profissional exigia do professor o domínio do saber fazer, ou seja, dos saberes relativos à prática de um ofício a ensinar. As novas demandas tecnológicas introduzidas na sociedade atual exigem um novo perfil profissional para o professor da educação profissional, o que pressupõe investimentos para um processo de formação contínua com base em outras concepções teóricas capazes de reestruturar e reconstruir os saberes docentes desses professores.

O perfil profissional do docente é necessariamente outro. O padrão do mestre artesão, da oficina escola, onde o aluno repetia séries metódicas de aprendizagem não atende mais a realidade do mundo do trabalho. $O$ saber fazer como requisito para ser professor já não é suficiente, pelo contrário, apresenta grandes limitações pedagógicas e teóricas em relação às práticas que ensina. Nesse contexto, o desafio que se coloca para essas instituições é o de oportunizar o acesso de seus estudantes ao mundo das conquistas científicas e tecnológicas. Para isso, faz-se necessário refletir sobre como superar a função mediadora dos interesses do capital historicamente assumida, sobretudo por essa rede de escolas.

A inclusão política, econômica e social da maioria da população foi o mote da criação dos Institutos Federais. Todavia, o acesso ao saber precisa tornar-se ferramentas que propiciem aos sujeitos problematizarem a realidade e, dessa forma, transformar-se em condição determinante de consciência e democracia. A escola está inserida em um contexto capitalista e é nesse contexto que ocorrerá o trabalho pedagógico. Urge que, a partir de um trabalho em equipe, as convergências e divergências dessa lógica possam ser discutidas e acatadas como diretrizes pedagógicas. A atenção à nova organização do mundo produtivo e aos impasses sociais que estão sendo gerados precisa fazer parte do contexto profissional do professor.

O desenvolvimento científico e tecnológico tem colocado em xeque o trabalho assalariado. A sociedade industrial, mecanizada e de produção em massa presente nos sistemas tayloristas e fordista, está sendo substituída pela terceirização, flexibilização das empresas, valorização do trabalho em equipe e do trabalhador polivalente. Outro contexto social está surgindo com mudanças que exigem novos profissionais e professores aptos para prepará-los.

Os Institutos Federais foram criados como um projeto pautado na inclusão social. Para isso, os professores devem possibilitar aos estudantes o acesso ao conhecimento e ao desenvolvimento de atitudes e de habilidades que os instrumentalizem para atuar 
diante dessas mudanças em diferentes contextos. Assim, as finalidades da educação profissional foram expandidas e passaram a incluir ações em programas de extensão, pesquisa aplicada, produção cultural, bem como divulgação científica e tecnológica. Programas como o PRONATEC, CERTIFIC, PROEJA, dentre outros, passaram a fazer parte do contexto educacional dos Institutos Federais. Essa nova organização institucional trouxe implicações para o trabalho docente. $O$ cotidiano da instituição apresenta uma configuração que exige do professor lidar com obstáculos, adaptar-se às mudanças e atuar em um contexto diversificado, que exige reconstrução e formação para lidar, de forma crítica e transformadora, com tantos desafios que a nova organização institucional apresenta.

Ensinar para a memorização e a repetição não é mais suficiente. É improrrogável a necessidade de desenvolver o pensamento abstrato, a capacidade de pensar, de criar, que resulta da articulação entre conteúdo e método, produto e processo, pensamento e ação, como condições para a constituição da cidadania capaz de superar a exclusão e construir uma nova sociedade. São desafios que os gestores e a equipe pedagógica precisam enfrentar a partir de planejamentos e organização de processos formativos consistentes e bem fundamentados.

Nessa perspectiva, a organização institucional constitui-se, ela própria, em objeto de conhecimento para a formação. Conhecer a organização institucional e o perfil do profissional docente é pressuposto para a proposição de um modelo de formação continuada para os professores. $O$ passo inicial é compreender a docência no âmbito da educação profissional atrelada ao mundo do trabalho e da tecnologia. Integrar conhecimentos da área específica aos conhecimentos pedagógicos vai subsidiar o planejamento das atividades de ensino de modo a favorecer a transposição do conhecimento científico e tecnológico que será construído pelo aluno.

$\mathrm{O}$ trabalho docente no âmbito da educação profissional apresenta um viés voltado para a prática, o que pressupõe a aplicabilidade de conhecimentos e habilidades instrumentais, além de produzir e inovar na área profissional e tecnológica. Isso implica a necessária integração entre organização institucional, formação docente peculiar e desenvolvimento pessoal no contexto investigado. Superar o modelo social historicamente perpetuado constitui o grande desafio. Enfrentar preconceitos e o reducionismo pedagógico aponta um caminho longo e árduo a ser trilhado no interior dessas instituições. Uma nova cultura formativa precisa ser instituída para promover mudanças paradigmáticas e romper com práticas ainda presentes, atuantes e muito fortes.

Refletir sobre necessidades formativas docentes no contexto do IFTM cria a possibilidade de desencadear um diálogo participativo entre os atores visando à construção de um modelo de formação continuada docente. O professor e o seu trabalho são o ponto de partida, seja como ser humano individual, seja como social, mas sobretudo como um ser em relações, capaz de produzir seus meios de vida contando com o conhecimento acumulado pela humanidade. Um ser que se educa para educar outros seres humanos.

Contextualizar o momento atual do ponto de vista social, cultural, econômico auxilia na compreensão dos desafios que precisam ser enfrentados na construção do 
BORGES, E. F.

processo de tornar-se professor. O vínculo institucional é fundamental na organização e condução de uma proposta formativa.

\section{A REDE FEDERAL DE EDUCAÇÃO PROFISSIONAL, CIENTÍFICA E TECNOLOGICA}

A Rede Federal de Educação Profissional, Científica e Tecnológica e os Institutos Federais de Educação, Ciência e Tecnologia surgiram com a Lei no 11.892, de 29 de dezembro de 2008. Qualificar profissionais para atender demandas do setor produtivo é o objetivo da Rede (BRASIL, 2008).

Para conhecer melhor os entendimentos sobre Educação Profissional e Tecnológica e as visões de mundo presentes na proposta de criação dos Institutos Federais, Vasconcellos (2019, p. 125) analisa duas perspectivas, quais sejam:

[...] a concepção de educação politécnica, de inspiração marxista, integrada e com vistas à emancipação humana; e a teoria do capital humano, surgida nos anos 1960 nos Estados Unidos e apropriada fortemente pela educação brasileira com o avanço da hegemonia econômica, cultural e política do neoliberalismo no país.

A Teoria do Capital Humano serviu de subsídio para fundamentar várias reformas educacionais do final do século XX e início do século XXI (BORGES; SOUZA ARAÚJO, 2019). Para essa teoria, as escolas devem-se adequar às necessidades do mercado de trabalho. No Brasil, a Teoria do Capital Humano vai influenciar o cenário educacional, principalmente a partir da década de 1960.

Durante o período militar, sob a liderança de Valnir Chagas, vários ajustes foram feitos na área educacional, que culminaram na reforma do ensino superior - por meio da Lei $n^{\circ}$ 5.540, de vinte e oito de novembro de 1968, que fixa Normas de Organização e Funcionamento do Ensino Superior e sua articulação com a Escola Média e dá outras providências, e da Reforma do Ensino de $1^{\circ}$ e de $2^{\circ}$ Graus, com a Lei no 5.692 , de onze de agosto de 1971, que fixa as Diretrizes e Bases para o Ensino de $1^{\circ}$ e de $2^{\circ}$ Graus e dá outras providências.

A Lei n. 5.692/71 determina a obrigatoriedade do ensino profissionalizante, que passa a ser referência de organização do ensino incluindo o secundário. Essa inversão do profissional em relação ao secundário rompe com uma tradição da educação brasileira. Todavia, isso ocorre por pouco tempo e fica mais no plano legal. Com essas medidas, é implantada a concepção pedagógica adotada oficialmente, a tecnicista.

Havia uma aceitação irrestrita da Teoria do Capital Humano, elaborada por Theodore William Schultz (1973), cujo pressuposto fundamental era que mais educação significa melhores salários e mais promoção social. Essa teoria vincula o conceito de capital humano a uma função agregada, de caráter macroeconômico-social entre as nações e as diferenças e desigualdades entre grupos sociais ou entre os indivíduos.

$\mathrm{Na}$ perspectiva dessa teoria, cabe à educação preparar os indivíduos para a aplicação de técnicas e ferramentas de gestão, o que reduziria o custo de produção e estimularia o crescimento da economia. Com esse novo enfoque, a partir dos anos de 1950, a educação transforma-se em uma atividade lucrativa, um investimento de aplicação do capital, e define a relação trabalho-educação na sociedade capitalista. Essa era a premissa da Teoria do Capital Humano, cuja origem e base de sustentação ocorre 
numa conjuntura pelo desenvolvimento capitalista marcado pelo crescimento econômico, pelo fortalecimento dos Estados de Bem-Estar Social e pela confiança na conquista do pleno emprego.

O contexto que propiciou o surgimento do conceito de capital humano correspondeu a uma fase áurea do modo de regulação fordista de desenvolvimento econômico, o qual explicita, paradoxalmente, os seus profundos limites. A Teoria do Capital Humano concebe o homem não como ser histórico-social, mas como homo economicus. Esse homem, responsável pela maximização da produção e do lucro, é livre nas suas escolhas e no seu consumo. $O$ fator econômico, considerado determinante das ações humanas, mobilizaria o homem nas suas iniciativas e conquistas.

Nessa perspectiva, a educação passa a ser um componente do fator econômico, como um capital individual que teria consequências sobre o capital social. A educação desencadearia a sociedade capitalista a atingir o pleno desenvolvimento e a modernização, eliminando as desigualdades de renda sem, no entanto, abalar as estruturas que produzem essa desigualdade.

Por ser uma teoria elaborada segundo a ótica da classe burguesa, não aborda as contradições sociais construídas na relação capital-trabalho e, assim, mascara a natureza ideológica embutida no vínculo linear entre educação e desenvolvimento. $O$ conceito de capital humano assume o caráter ideológico inclusive quando tenta esfumaçar a divisão social de classes ao conferir ao indivíduo a responsabilidade e a liberdade de buscar a ascensão social (FRIGOTTO, 1999).

Acreditava-se na possibilidade de generalização da indústria e, em decorrência disso, ocorreria o desenvolvimento social resultado do pleno emprego e da diminuição das desigualdades. A crise dos anos de 1970 já evidenciava a precariedade desse pressuposto, quando ocorre uma mudança profunda na base técnica de produção que substitui o fordismo pelo toyotismo:

O modelo fordista apoiava-se na instalação de grandes fábricas operando com tecnologia pesada de base fixa [...]; supunha a estabilidade no emprego. [...] o modelo toyotista apoia-se em tecnologia leve, de base microeletrônica e flexível, e opera com trabalhadores polivalentes que [...] disputem diariamente cada posição conquistada, vestindo a camisa da empresa (SAVIANI, 2013, p. 429).

No Brasil, durante o período da ditadura militar, as duas reformas - a universitária, de 1968 , e a do ensino de $1^{\circ} \mathrm{e} 2^{\circ}$ graus, em 1971 - estruturaram o sistema de ensino dentro dos parâmetros produtivistas, tecnicistas e economicistas, inspirados nessa formulação teórico-ideológica.

Até hoje, os adeptos desta ideologia não respondem à seguinte questão: os países pobres e as populações pobres assim são porque investem pouco em educação ou tem pouca educação porque são pobres? Uma visão que, além de reduzir a educação de um direito social e subjetivo a um serviço mercantil, falseia e obscurece as reais relações sociais que produzem a desigualdade. (FRIGOTTO; CIAVATTA, 2016, p. 30, 31). 
BORGES, E. F.

Com a superação do otimismo gerado pela Teoria do Capital Humano, a sociedade mantém os mesmos referenciais economicistas, mas relega as demandas sociais previstas e a crença no pleno emprego. Nesse novo momento,

[...] é o indivíduo que terá de exercer sua capacidade de escolha visando a adquirir os meios que lhe permitam ser competitivo no mercado de trabalho. $\mathrm{E}$ o que ele pode esperar das oportunidades escolares já não é o acesso ao emprego, mas apenas a conquista do status de empregabilidade. (SAVIANI, 2013, p. 430).

A perspectiva educacional continua sendo economicista e produtivista, bem como importante na sua relação com o mercado. Porém, trata-se agora de um investimento em capital humano individual que habilita para a competição e não mais para o pleno emprego. Os diversos graus de escolaridade, além de retardar o ingresso no mercado de trabalho, amplia as condições de empregabilidade do indivíduo, sem a garantia de que o emprego vá acontecer.

Portanto, na perspectiva da Teoria do Capital Humano, o objetivo das escolas seria proporcionar aos estudantes as condições satisfatórias ao mercado de trabalho. A educação se faz instrumento de um setor da sociedade externo a ela mesma, o mercado. A Teoria do Capital Humano foi operacionalizada no sentido de se apropriar de termos teórico-científicos para operá-los em favor do projeto de sociedade dado pelo Consenso de Washington. Ela se apresenta como o salvamento da educação em relação a paradigmas educacionais que seriam "retrógrados", inadequados às demandas do mundo globalizado.

O direcionamento da globalização no aspecto da educação fica ancorado na ideia de que o objetivo é a sobrevivência nesse mundo globalizado e não há alternativas. Projetos coletivos de mudança social, movimentos políticos de reformas estruturais na sociedade, tudo isso é soterrado pela ideia de que a globalização é o único dado que existe, do qual não se pode escapar e com o qual se deve trabalhar.

A ideologia do capital humano fundamenta-se no argumento de que faltam profissionais qualificados para ocupar as vagas no mundo da produção flexível e que a educação tal como existe é insuficiente para contribuir para o suprimento dessa demanda do mercado. Inicia-se um processo de pressões exógenas à educação básica, principalmente no sentido de torná-la a ponte técnica e profissionalizante entre o jovem e o mercado de trabalho.

O objetivo da Teoria do Capital Humano é reduzir o saber e a técnica produzidos até então ao ponto de torná-los instrumentais para inserção e manutenção no mercado de trabalho. Para a sociedade neoliberal, em sua dimensão pedagógica, operacionalizada pela pedagogia das competências, todo o conhecimento produzido pela humanidade deve servir como ferramenta para que cada indivíduo sobreviva e sobressaia na competitividade intensa de uma sociedade de pessoas livres e iguais.

De acordo com Frigotto e Ciavatta (2003), os ideólogos do capital humano suprimem de sua narrativa - não por ignorância, mas por escolha - a desigualdade estrutural das sociedades capitalistas. Quando se trata das sociedades e economias de desenvolvimento tardio, especialmente o Brasil, um dos países em desenvolvimento com o maior abismo social, tal estratégia de dissimulação da realidade histórica é mais danosa. 
Quando o direito à educação universal ainda não é um fato como no Brasil pósConstituição de 1988, esse tipo de tese se infiltra com mais facilidade do que em países que já conheceram a universalidade e qualidade da educação. No Brasil, por causa de uma experiência histórica de exclusão de boa parte da população no que se refere à educação, propaga-se rapidamente a certeza de que quanto mais rápida e prática for sua formação, mais chances de vitória no mercado de trabalho existirão.

Há um imperialismo simbólico, em que o discurso obscurece fatos sociais, educacionais, econômicos, culturais. Termos como polivalência, qualidade total, competências, cidadão produtivo e empregabilidade substituem os vocábulos educação integral, omnilateral, laica, unitária, politécnica, tecnológica e emancipatória nas reformas ocorridas a partir da década de 1970 e 1980.

O que ocorre é a transferência da responsabilidade de problemas sociais - como analfabetismo, desemprego, criminalidade - do coletivo para o indivíduo, para a esfera privada (FRIGOTTO, 2005). Além dessa transferência de responsabilidades do plano coletivo para o individual, acresce-se ainda uma realocação acerca das desigualdades entre as nações. A partir dessas teorias, o fato de o país alcançar o desenvolvimento ou não recai sobre o diferencial de escolaridade e de saúde dos trabalhadores (CIAVATTA; FRIGOTTO, 2003).

Esse fato desconsidera as desigualdades sociais de classe entre os países e ignora a possível contribuição da educação, num sentido amplo, para reforçá-las ou dirimi-las. Como o Brasil, por exemplo, poderia desenvolver-se com mais investimentos em educação com esse viés tecnicista? Que tipo de desenvolvimento seria esse? Seria de fato para brasileiros e brasileiras ou para o suprimento de força de trabalho minimamente qualificada, com o objetivo de ocupar vagas precarizadas num mercado de trabalho dotado de alto grau de mecanização e informatização?

Há que se resgatar que, desde o início do século XX, pensadores brasileiros, como Anísio Teixeira, propunham a universalização da educação. Acontece que opostamente, no plano legal e, ainda mais grave, no plano prático, a universalização da educação começa a ser reivindicada no final da década de 1980 , com a promulgação de uma nova Constituição. Isto é, nos países altamente desenvolvidos, a educação é um direito para a população e um ponto estratégico para o Estado (CIAVATTA; FRIGOTTO, 2003). Nos marcos do capitalismo brasileiro, por outro lado, a educação não foi universalizada na prática até os anos 2019 e nem considerada uma dimensão estratégica para o Estado.

A iniciativa das mudanças na Educação Profissional e Tecnológica no início dos anos 2000 busca reverter essa constante na educação brasileira. Os Institutos Federais, já de acordo com outra perspectiva, da educação integrada, são tratados por seu idealizador como sem semelhantes em nenhum outro país por suas características políticopedagógicas radicalmente vinculadas ao conceito de educação politécnica. $O$ trabalho, nos marcos desse conceito, é entendido como princípio educativo e a politecnia é a concepção e realização da educação como domínio dos fundamentos científicos das técnicas praticadas nos processos produtivos atuais (SAVIANI, 2007).

De acordo com Pacheco (2011), o Instituto Federal não formaria apenas para o mercado de trabalho, mas para o mundo do trabalho; uma acepção mais ampla enquanto fundamento formativo e ontológico da própria condição humana. Além dessa 
caracterização em matéria de concepção filosófico-política de educação profissional, há ainda uma diferenciação no que tange à diversidade de estágios de educação das modalidades atendidas pelo Instituto Federal: define-se, pela lei de criação, que os Institutos Federais atendam desde a formação técnica de nível médio ( $50 \%$ das vagas), passando por licenciaturas (20\%), até graduações tecnológicas e pós-graduação lato sensu e stricto sensu.

A Educação Profissional e Tecnológica Brasileira, após a criação dos Institutos Federais, seria "uma educação vinculada a um Projeto Democrático, comprometido com a emancipação dos setores excluídos de nossa sociedade" (PACHECO, 2011). O que se torna fundamental nesse ponto é questionar se estariam os gestores, as linhas de frente em cada reitoria de cada Instituto Federal e, além disso, a comunidade de professores e técnicos administrativos, cada um em seu nicho de atuação, organizados em torno do mesmo projeto ao qual Pacheco se refere.

Esse é um desafio a ser enfrentado pelos gestores dessas instituições. Criados em um contexto do mundo globalizado e suas mazelas, mesmo sendo uma proposta inovadora em termos de referenciais teóricos, traduzi-los para o cotidiano da prática pedagógica não será uma tarefa fácil. Os Institutos Federais são autarquias criadas para responder aos desafios de natureza política e econômica do setor produtivo da sociedade brasileira. São, portanto, instituições de ensino diferenciadas no contexto das demais instituições de educação no Brasil, o que exige um olhar próprio, peculiar, quando se pretende compreendê-las. As finalidades, previstas na Lei $n^{\circ} 11.892 / 2008$, abrangem diferentes níveis de atuação, indo desde a educação básica até ao ensino superior, incluindo pós-graduação lato e stricto sensu. Compreende diferentes modalidades de educação profissional, envolvendo também todos os níveis de ensino, além da exigência de articulação com o setor produtivo. Prevê a oferta de licenciaturas, de engenharias e a realização de pesquisas aplicadas. Deve, ainda, constituir-se em centro de referência no apoio às instituições públicas de ensino para destacar algumas de suas atribuições. Como pode-se observar, essas finalidades tornam a situação institucional bastante complexa.

Tais finalidades exigem perfis profissionais diferenciados das demais instituições escolares para fazerem frente às diversificadas áreas de atuação previstas pela legislação, que determinam necessidades formativas específicas. Os professores dos Institutos Federais atuam, portanto, desde o ensino fundamental, passando pelo técnico de nível médio até o superior, incluindo graduação, pós-graduação lato e stricto sensu.

Fazem parte do quadro institucional as seguintes modalidades de cursos: nível médio integrado, para os concluintes do ensino fundamental e para o público da educação de jovens e adultos; formação inicial e continuada de trabalhadores, objetivando a capacitação, o aperfeiçoamento, a especialização e a atualização de profissionais, em todos os níveis de escolaridade, nas áreas da educação profissional e tecnológica; nível superior, cursos superiores de tecnologia, cursos de licenciatura, cursos de bacharelado e engenharia, cursos de pós-graduação lato sensu e stricto sensu.

Para atender a essas finalidades, a compreensão das necessidades formativas dos professores é fundamental na elaboração de um processo formativo para que esses professores possam atuar nos diferentes segmentos previstos para essas instituições. $O$ conhecimento dessas necessidades serão, portanto, essenciais para o delineamento de um modelo de [trans]formação continuada para esses professores. 
Nos Institutos Federais, além do ensino, fazem parte da atuação docente as atividades de gestão, pesquisa e extensão, o que compreende atuar em programas e projetos institucionais e pessoais. Essa conjuntura envolve uma atuação que vai do ensino básico ao superior na perspectiva profissional e uma clientela de jovens e adultos. Embora o perfil docente deva ser bem diferenciado, a legislação não prevê uma formação específica para esses professores. Este fato pressupõe a necessidade de uma formação que integre a Educação Básica e a Educação Superior à Educação Profissional.

\section{CONSIDERAÇÕES FINAIS}

A educação superior inserida no contexto da educação profissional e tecnológica a partir dos anos de 1978 será marcada de modo indelével pela influência do processo de colonização e pelo uso da mão de obra escrava, com reflexos constantes nas propostas de formação profissional sempre vistas com a pecha escravocrata.

Com a Teoria do Capital Humano surgida nos meados do século XX, ganha destaque a função economicista da educação, que passa a ser organizada em um contexto tecnicista e produtivista. Nos anos 1970, com a crise do capitalismo, há esgotamento da Teoria do Capital Humano e surge o conceito de empregabilidade que retira o foco das demandas coletivas, antes consideradas como capazes de desencadear o pleno emprego e o desenvolvimento social, e passa a considerar que a questão do sucesso profissional é restrita ao âmbito individual relacionado às competências e habilidades pessoais.

O desenvolvimento econômico ocorre mesmo com a redução drástica de recursos humanos. A inserção no mercado de trabalho, a partir daquele momento, passa a depender das competências individuais. Trata-se, como se observa, de uma continuidade do caráter economicista da educação, a confirmar o triunfo de uma escola produtivista/tecnicista em vigência desde o século XIX, sob a tutela da II Revolução Industrial, aos dias atuais. Nesse âmbito, a escola oscilaria para o lado da ciência e da técnica. Pleiteia-se, projetivamente, que a escola deva servir à prosperidade, ao progresso, ao desenvolvimento.

As demandas coletivas associadas à ideia do pleno emprego prevista na Teoria do Capital Humano eram uma falácia. $O$ desemprego já existente aumenta e torna-se um fenômeno estrutural, e milhares de seres humanos ficam à margem dos ganhos do capital. O fenômeno da globalização e suas nefastas consequências econômicas provocou um intenso processo migratório, em escala mundial, excluiu milhares de pessoas do convívio sociocultural determinado pelo desemprego, subemprego, desalento e outros adjetivos, transformando as sociedades em contextos desumanos, em que predomina a violência e a marginalidade.

Haverá saída para esse panorama desalentador? Faz-se necessário refletir sobre alternativas que resgatem o diálogo, a dignidade, a solidariedade, enfim, valores que proporcionem a reorganização socioeconômica e cultural em contextos humanos, em que o resultado do capital, as conquistas científicas e tecnológicas estejam a serviço do homem, sejam propulsoras do desenvolvimento humano e não do seu banimento. 
BORGES, E. F.

A Teoria do Capital Humano continua se direcionando para atender a um contexto socioeconômico baseado na exclusão, uma vez que não há lugar para todos na atual ordem econômica. Nesse contexto, consolida-se a pedagogia da exclusão, que incentiva a realização incessante de cursos para tornarem os indivíduos empregáveis e, assim, escaparem da condição de excluídos. E, nessa condição, mesmo com os mais diferentes títulos, ao permanecerem fora do mundo do trabalho, a responsabilidade é de cada um. O sistema de ensino profissional insiste em estabelecer essa relação entre qualificação profissional e emprego. E os professores também não conseguem formular uma proposta educacional mais humana e comprometida com o desenvolvimento integral dos jovens brasileiros.

Reverter essa situação, buscando o resgate da dignidade de milhares de seres humanos, é o desafio atual, para tirar da marginalidade milhares de pessoas para que possam usufruir das conquistas que a humanidade conseguiu com o capital e com o desenvolvimento científico e tecnológico. Colocar essas conquistas em prol do desenvolvimento humano e social, transformando o contexto social, político, econômico, cultural e educacional em territórios humanizados em que será possível viver com dignidade é o desafio que se apresenta na contemporaneidade.

Artigo recebido em: 17/01/2020

Aprovado para publicação em: 03/03/2020

PERSPECTIVE HISTORY OF PROFESSIONAL AND TECHNOLOGICAL EDUCATION IN BRAZIL: THE CONSTITUTION OF TEACHING IN HIGHER EDUCATION IN TIMES OF GLOBALIZATION

ABSTRACT: Analyzing higher education in the Federal Professional Education Network, in a context of globalization characterized as a complex and challenging reality, was the objective of this article. Having as a theoretical reference authors critical to the Theory of Human Capital, the study adopted as a methodological procedure, two interconnected movements: bibliographic and documentary research. Higher education in this education network is in the process of being structured and consolidated. The challenge is to rescue the enormous debt in relation to the majority of Brazilians condemned to marginality from a perverse historical heritage, and accentuated by the globalized economic rearrangement that excludes thousands of people from conquests that humanity has achieved capital and scientific and technological development.

KEYWORDS: Higher Education. Professional education. Technological education. Globalization.

HISTÓRIA PERSPECTIVA DE LA EDUCACIÓN PROFESIONAL Y TECNOLÓGICA EN BRASIL: LA CONSTITUCIÓN DE LA ENSEÑANZA EN LA EDUCACIÓN SUPERIOR EN TIEMPOS DE GLOBALIZACIÓN

RESUMEN: Analizar la educación superior en la Red Federal de Educación Profesional, en un contexto de globalización caracterizado como una realidad compleja y desafiante, fue el objetivo de este artículo. Teniendo como referencia teórica a autores críticos con la Teoría del Capital Humano, el estudio adoptó como procedimiento metodológico, dos movimientos interconectados: la investigación bibliográfica y documental. La educación superior en esta red educativa está en proceso de estructuración y consolidación. El desafío que surge es rescatar la enorme deuda con la 
mayoría de brasileños condenados a la marginalidad de una herencia histórica perversa, y acentuada por el reordenamiento económico globalizado que excluye a miles de personas de las conquistas que la humanidad ha logrado a través de capital y desarrollo científico y tecnológico.

PALABRAS CLAVE: Educación superior. Educación profesional Educación Tecnológica. Globalización.

\section{REFERÊNCIAS}

BORGES, E. F.; FAGIANE, C. C. Educação e trabalho no contexto da sociedade contemporânea. Argumentos Pró-Educação, Pouso Alegre, v. 3, no 9, p. 536-557, set. dez. 2018. DOI: http://dx.doi.org/10.24280/ape.v3i9.381.

BORGES, E. F.; CECÍLIO, S. O trabalho docente no Brasil [década de 1950 aos dias atuais]: a precarização no contexto de (re) democratização. Revista Holos, ano 34, v. 5. 2018.

BORGES, E. F.; ARAÚJO, J. C. S. Educação profissional, dualidade estrutural e neoprodutivismo. Revista Educação em questão, v. 57, n. 52, p. 1-33, e-16002. abr./jun. 2019.

BRASIL. Decreto 7.566, em 23 de setembro de 1909, crêa nas capitaes dos Estados da República Escolas de Aprendizes Artífices, para o ensino profissional primário e gratuito. Disponível em: https://www2.camara.leg.br/legin/fed/decret/1900-1909/decreto-756623-setembro-1909-525411-norma-pe.html. Acesso em: 13 maio 2019.

BRASIL. Constituição dos Estados Unidos do Brasil, de 10 de novembro de 1937. Disponível em: http://www.planalto.gov.br/ccivil_03/constituicao/constituicao37.htm. Acesso em: 13 maio 2019.

BRASIL. Lei n. 378, de 13 de janeiro de 1937. Dá nova organização ao Ministério da Educação e Saúde Pública. Disponível em: https://www2.camara.leg.br/legin/fed/lei/1930-1939/lei-378-13-janeiro-1937-398059publicacaooriginal-1-pl.html. Acesso em: 19 jul. 2019.

BRASIL. Decreto-lei n. 4.127, de 25 de fevereiro de 1942. Estabelece as bases de organização da rede federal de estabelecimentos de ensino industrial. Disponível em: https://www2.camara.leg.br/legin/fed/declei/1940-1949/decreto-lei-4127-25-fevereiro1942-414123-publicacaooriginal-1-pe.html. Acesso em: 19 jul. 2019.

BRASIL. Lei n. ${ }^{\circ}$ 4.024, de 20 de dezembro de 1961. Fixa as Diretrizes e Bases da Educação Nacional. Rio de Janeiro: Livraria Agir, 1968. (Coleção AEC). 
BRASIL. Decreto n. 60.731, de 19 de maio de 1967. Transfere para o Ministério da Educação e Cultura os órgãos de ensino do Ministério da Agricultura e dá outras providências. Disponível em: https://www2.camara.leg.br/legin/fed/decret/19601969/decreto-60731-19-maio-1967-401466-norma-pe.html. Acesso em: 12 jan. 2020.

BRASIL. Lei $\mathbf{n} .^{\circ}$ 5.540, de 28 de novembro de 1968. Fixa normas de organização e funcionamento do ensino superior e sua articulação com a escola média, e dá outras providências. Disponível em:

https://presrepublica.jusbrasil.com.br/legislacao/109783/lei-5540-68. Acesso em: 04 jan. 2019.

BRASIL. Lei n..$^{\circ}$.692, de 11 de agosto de 1971. Fixa as Diretrizes e Bases para o Ensino de $1^{\circ}$ e de $2^{\circ}$ Graus e dá outras providências. 1971. Disponível em:

http://www2.camara.leg.br/legin/fed/lei/1970-1979/lei-5692-11-agosto-1971-357752-

publicacaooriginal-1-pl.html. Acesso em: 8 fev. 2018.

BRASIL. Lei n. 6.545 de 30 de junho de 1978. Dispõe sobre a transformação das Escolas Técnicas Federais de Minas Gerais, do Paraná e Celso Suckow da Fonseca em Centros Federais de Educação Tecnológica e dá outras providências. Disponível em:

http://www.planalto.gov.br/ccivil_03/LEIS/L6545.htm. Acesso em: 16 jan. 2020.

BRASIL. Decreto n. ${ }^{\circ}$ 2. 208, de 17 de abril de 1997. Regulamenta o $§ 2^{\circ}$ do art. 36 e os artigos 39 a 42 da Lei 9.394, de 20 de dezembro de 1996, que estabelece as diretrizes e bases da educação nacional. 1997. Disponível em: http://portal.mec.gov. Acesso em: 20 jan. 2018.

BRASIL. Constituição República Federativa do Brasil. Brasília. Senado Federal Centro Gráfico. 1988.

BRASIL. Linha do tempo. Rede Federal de Educação Profissional e Tecnológica. Fundação Joaquim Nabuco. Documentação. 2009. Disponível em:

http://portal.mec.gov.br/setec/arquivos/centenario/linha.pdf. Acesso em: 20 set. 2020.

BRASIL. Decreto n. 9.235, de 15 de dezembro de 2017. Dispõe sobre o exercício das funções de regulação, supervisão e avaliação das instituições de educação superior e dos cursos superiores de graduação e de pós-graduação no sistema federal de ensino. Disponível em: http://www.planalto.gov.br/ccivil_03/_Ato2015-

2018/2017/Decreto/D9235.htm\#art107. Acesso em: 16 jan. 2020.

BRASIL. Lei n. 8.948, de 8 de dezembro de 1994 - dispõe sobre a instituição do Sistema Nacional de Educação Tecnológica e dá outras providências. Disponível em: http://www.planalto.gov.br/ccivil_03/LEIS/L8948.htm. Acesso em: 12 jan. 2020.

BRASIL. Decreto n..$^{\circ}$ 5.154, de 23 de julho de 2004. Regulamenta o $\S 2^{\circ}$ do art. 36 e os arts. 39 a 41 da Lei no 9.394 de 20 de dezembro de 1996, que estabelece as diretrizes e 
bases da educação nacional, e dá outras providências. 2004. Disponível em: http://www.planalto.gov.br. Acesso em: 20 jan. 2018.

BRASIL. Lei n. 9.394, de 20 de dezembro de 1996 - Estabelece as diretrizes e bases da educação nacional. In: LDB - Lei de Diretrizes e Bases da Educação Nacional. Biblioteca Digital da Câmara dos Deputados. 7a Edição. Brasília: Centro de documento e informação, 45 p., 2012.

BRASIL. Lei n. 11.892, de 29 de dezembro de 2008, institui a Rede Federal de Educação Profissional, Científica e Tecnológica, cria os Institutos Federais de Educação, Ciência e Tecnologia, e dá outras providências. Disponível em:

http://www.planalto.gov.br/ccivil_03/_ato2007-2010/2008/lei/l11892.htm. Acesso em: 13 maio2019.

CIAVATTA, M. 0 trabalho docente e os caminhos do conhecimento: a historicidade da Educação Profissional. $1^{\text {a }}$ edição. Rio de Janeiro: Lamparina, 2015.

FRIGOTTO, G. (Org.). Educação e crise do trabalho: perspectivas de final de século. Petrópolis, RJ: Vozes, 1999.

FRIGOTTO, G.; CIAVATTA, M. Educação Básica no Brasil na década de 1990: subordinação ativa e consentida à lógica do mercado. Educ. Soc. Campinas, vol. 24, n. 82, p. 93-130, abril, 2003.

FRIGOTTO, G.; CIAVATTA, M. (Org.). Teoria e educação no labirinto do capital. 4. ed. São Paulo: Expressão Popular, 2016.

FRIGOTTO, G. Concepções e mudanças no mundo do trabalho e o Ensino Médio. In:

FRIGOTTO, G., CIAVATTA, M.; RAMOS, M. Ensino Médio Integrado - concepções e contradições. São Paulo, Editora Cortez, 2005.

MINCER, J. Investment in Human Capital and personal income distribution. In: Journal of Political Economy, vol. 66, n. 4, 1958, p. 281-302.

PACHECO, E. Institutos Federais - uma revolução na educação profissional e tecnológica. Brasília: Moderna, 2011.

PEREIRA, S. Centenário da Rede de Educação Profissional. EPSJV/Fio Cruz. 2018. Disponível em: http://www.epsjv.fiocruz.br/noticias/reportagem/centenario-da-rede-deeducacao-profissional. Acesso em: 20 set.2020.

SAVIANI, D. Trabalho e educação - fundamentos ontológicos e históricos. In: Revista 
BORGES, E. F.

Brasileira de Educação, v. 12, n. 34, p. 152-180, jan./abr. 2007.

SAVIANI, D. História das ideias pedagógicas no Brasil. 4. ed. Campinas: Autores Associados, 2013.

SCHULTZ, T. W. O valor econômico da educação. Tradução P. S. Werneck. 2. ed. Rio de Janeiro: Zahar Editores, 1973.

TADEU da SILVA. T. A escola cidadã no contexto da globalização: uma introdução. In: HERON da SILVA, L. (Org.). A escola cidadã no contexto da globalização. $4^{a}$ edição. Petrópolis: Vozes, 2000.

VASCONCELLOS, I. S de. As diferentes concepções sobre a identidade e os objetivos dos Institutos Federais: o caso do Instituto Federal do Triângulo Mineiro. In: BATISTA, E. L; MÜLLER, M. T. (Orgs). Instituições de Educação Profissional no Estado de Minas Gerais. Uberlândia: Navegando Publicações. 2019.

\footnotetext{
Elisabete Ferreira Borges: Possui graduação em Pedagogia - Faculdades Integradas São Tomás de Aquino (1972). Especialização em Didática - Faculdade Barão de Mauá, Especialização em Planejamento Universitário pela Pontifícia Universidade Católica do Rio de Janeiro e Mestrado em Educação (2005) - Universidade de Uberaba. É doutora em Educação pela UNIUBE, atuando como Técnica em Assuntos Educacionais no Instituto Federal de Educação, Ciência e Tecnologia do Triângulo Mineiro, na Pró-Reitoria de Pesquisa e Inovação.

Orcid: https://orcid.org/0000-0002-9157-3722

E-mail: elisabete_borges@uol.com.br
}

Este periódico utiliza a licença Creative Commons Attribution 3.0, para periódicos de acesso aberto (Open Archives Iniciative - OAI) 